\title{
Um Exercício Filosófico Sobre o Trabalho do Professor de Matemática com a Investigação Matemática
}

\author{
A Philosophical Exercise on the Work of the Mathematics Teacher with Research \\ Mathematical
}

\author{
Paulo Wichnoski ${ }^{1}$ \\ Tiago Emanuel Klüber ${ }^{2}$
}

\section{Resumo}

Neste ensaio buscamos compreender, sob uma perspectiva epistêmica, saberes e conhecimentos imprescindíveis ao professor de matemática ao estar-com ${ }^{3}$ a Investigação Matemática. Para isso, consideramos a concepção de saber e de conhecer explicitada por Bombassaro (1993) e interrogamos: que saberes e conhecimentos são imprescindíveis ao professor ao estar-com a Investigação Matemática no ensino da matemática? Diante do interrogado, concluímos que, dentre outros aspectos, saber investigar, conhecer matemática, saber sobre a Investigação Matemática e conhecer a Investigação Matemática, destacam-se como aspectos imprescindíveis ao professor no trabalho investigativo. Salientamos a impossibilidade de dicotomizar saber e conhecer e os prejuízos advindos da adoção unilateral de uma dessas dimensões.

Palavras-chave: Ensino de matemática; Investigação Matemática; Epistemologia.

\section{Introdução}

É fato que a Investigação Matemática vem ganhando relevância no âmbito das pesquisas em Educação Matemática. Isso pode ser visto mediante a

\footnotetext{
${ }^{1}$ Mestre em ensino. Docente do curso de matemática da Faculdade de Ampére - FAMPER. Email:wichnoski@gmail.com.

${ }^{2}$ Doutor em Educação Científica e Tecnológica. Docente do Colegiado de Matemática, Unioeste, Cascavel. Coordenador do Programa de Pós-Graduação em Educação em Ciências e Educação Matemática, PPGECEM, Unioeste, Cascavel. Docente Permanente do Programa de PósGraduação em Ensino - PPGEn, Unioeste, Foz do Iguaçu. Docente Colaborador do Programa de Pós-Graduação em Educação - PPGE, Unioeste, Cascavel. E-mail: tiagokluber@gmail.com.

${ }^{3}$ estar-com está ligado à concepção heideggeriana que diz do ser-com, o qual significa estar junto a, ao existir no mundo. Essa postura, de ser-com, diz da abertura do modo de ser para outros entes, entendidos como pessoas ou não (FERREIRA; PAULO, 2014).
} 
emergência contínua de trabalhos vinculados a essa tendência, os quais são desenvolvidos sob diferentes prismas.

Exemplos de pesquisas emergentes são encontrados em Carneiro (2001), Ponte e Rocha (2006) e, Abreu e Passos (2008). Carneiro (2001) busca o entendimento daquilo que é possível efetuar em um Curso de Licenciatura, no que tange à formação de um professor de Matemática, atualizado em Educação Matemática, identificado com esta área de pesquisa e capaz de (re)produzir conhecimento. Isto é, um professor criativo, que percebe os problemas e busca alternativas, libertando-se do tradicionalismo do ensino e podendo transformar a sua prática pedagógica.

Ponte e Rocha (2006) realizaram um trabalho com o objetivo de verificar o alcance do desenvolvimento de uma prática de Investigação Matemática com alunos do $7^{0}$ ano de escolaridade. Abreu e Passos (2008) se debruçaram sobre a prática pedagógica de uma das pesquisadoras, buscando compreender quais as contribuições que um trabalho com tarefas exploratório-investigativas traz para o processo de reflexão sobre a própria prática e para a transformação de alguns saberes docentes e discentes.

Entretanto, embora existam estudos que se voltem à Investigação Matemática e suas diferentes facetas como campo de pesquisa, este, ainda, é muito vasto, com inúmeras possibilidades de estudos.

Quando nos referimos às diferentes facetas da Investigação Matemática, estamos querendo dizer das diversas possibilidades de pesquisa que se abrem, enfocando-a. Dentre elas, podemos citar as pesquisas que a tratam concomitantemente à formação de professores, como prática pedagógica e como atividade de ensino e aprendizagem.

Ocorre que, em geral, as pesquisas realizadas assumem uma concepção de Investigação Matemática, em certo sentido, dogmática, não considerando as reflexões epistemológicas acerca do problema da produção do conhecimento nessa área. 
Por exemplo, a perspectiva de Ponte, Brocardo e Oliveira (2013) a Investigação Matemática se trata de "uma atividade de ensino-aprendizagem" que busca conduzir o aluno a pensar e construir o conhecimento de maneira autônoma e "se relacionam, de muito perto com a resolução de problemas." (PONTE; BROCARDO; OLIVEIRA, 2013, p. 22).

Em resumo, entende-se a Investigação Matemática como uma metodologia de ensino que busca, por meio de tarefas que se apresentam de forma mais aberta - podendo assumir diversas formas de resolução -, conduzir o aluno a pensar e construir o conhecimento de maneira relativamente autônoma, criando situações que o leve a raciocinar e entender o novo conceito.

Essa caracterização, mesmo que lance luzes sobre o entendimento do que vem a ser uma Investigação Matemática, deixa uma lacuna na compreensão do que ela é efetivamente no contexto da Educação Matemática. Não há a preocupação com reflexões epistemológicas, crendo que ela (a Investigação Matemática) nos é dada "absolutamente e não meramente por obra da função intermediaria do conhecimento" (HESSEN, 1980, p. 38).

Ao afirmarem que "As investigações matemáticas [...] se relacionam, de muito perto, com a resolução de problemas" (PONTE; BROCARDO; OLIVEIRA, 2013, p. 22), deixam margem para que essa tendência se dilua e até mesmo seja confundida com outra. Em suma, há apenas uma compreensão operacional e vaga de atividades de Investigação Matemática.

Frente a isso é que destacamos a necessidade de haver, por parte dos pesquisadores, um esforço de situá-la em uma discussão de cunho epistemológico, bem como os diversos aspectos que a caracterizam. Desse modo, a exemplo de outras áreas, como a Modelagem Matemática na Educação Matemática, é chegado o momento de transcender a fronteira das práticas que, em geral, se caracterizam como relatos de experiências e buscar teorizações mais latas que fortaleçam, refinem e até mesmo reformulem aquilo que é tomado como posto no tocante à Investigação Matemática. 
Mesmo que seja assumida a perspectiva de Ponte, Brocardo e Oliveira (2013) é preciso desvelar e compreender epistemologicamente alguns dos seus aspectos. Assim, diante da situação explicitada e das diversas possibilidades que se abrem, assumimos nesse trabalho o desafio de contribuir, lançando luzes aos apontamentos feitos acima e buscando discutir e compreender epistemologicamente aspectos que dizem do trabalho do professor com essa tendência. Em outras palavras, compreendemos que é na esfera do trabalho com a Investigação Matemática que saber e conhecer, enquanto conceitos epistêmicos podem alcançar a sua expressão mais plena.

Essa compreensão nos conduz a interrogar: que saberes e conhecimentos são imprescindíveis ao professor ao estar-com a Investigação Matemática no ensino da matemática? Essa interrogação guarda características de perguntas filosóficas, que não olham os objetos de dentro do mundo, mas colocam os objetos e, o próprio mundo, sob suspeita, portanto, podendo clarear aspectos que dificilmente seriam vistos sob uma perspectiva internalista.

De modo particular, essa interrogação solicita que os conceitos saber e conhecer sejam esclarecidos do ponto de vista epistemológico e para tanto, recorremos à obra de Bombassaro (1993).

Ressaltamos que essa obra aborda de maneira ímpar o tema e dialoga com os principais epistemólogos contemporâneos e filósofos da linguagem e hermenêutica. Por esse motivo, ela se constitui no eixo principal do nosso discurso, uma vez que sintetiza o debate. Considerando que a região de inquérito abordada neste ensaio se situa entre as Ciências Exatas (Matemática) e Humanas (Ensino) esses dois conceitos tendem a serem esclarecedores para lançar luzes ao interrogado.

Saber e conhecer se apresentam cotidianamente no senso comum como ações equivalentes ou muito próximas. São termos atribuídos a verbos tão usuais na linguagem diária que não nos damos conta de pensar na epistemologia em que cada um pode se assentar. 
Entretanto, se refletirmos sobre eles, veremos que podem ser tomados comoconceitos epistêmicos e manifestam sentidos distintos. Tal diferença, cunhada no próprio uso linguístico de cada um dos verbos, tem sido amplamente estudada principalmente pela filosofia da linguagem (BOMBASSARO, 1993).

O exposto requer um esclarecimento mais detido sobre cada um dos conceitos, para tematizarmos o nosso objeto de estudo que se constitui dos saberes e conhecimentos inerentes à esfera do trabalho com a Investigação Matemática.

\section{Sobre os conceitos epistêmicos: saber e conhecer}

Na história da filosofia, saber foi entendido como "ter por verdadeiro". Para Platão apud Bombassaro (1993), "saber é uma opinião verdadeira, sempre acompanhada de uma explicação e por um pensamento fundado" (BOMBASSARO, 1993, p. 19).

Segundo Ryle citado por Bombassaro (1993) existem dois sentidos para o verbo saber. O primeiro é aquele que se exprime no uso da expressão saber que..., a qual precede uma oração que menciona um fato. Esse sentido revela uma forma de saber proposicional, pois o seu conteúdo é sempre expresso por uma proposição, que pode ser verdadeira ou falsa. Por exemplo, a expressão sabemos que a Investigação Matemática auxilia no ensino de matemática menciona 0 fato de que o ensino de matemática pode se dar com o auxílio da tendência Investigação Matemática, a qual pode ser verdadeira ou falsa.

O segundo sentido diz do saber como, do inglês know how, que pode ser traduzido para a língua portuguesa como saber fazer. Essa expressão sempre precede um verbo, indicando uma ação qualquer. Assim, o saber fazer se refere às ações das quais podemos qualificá-las como verdades ou falsidades, conforme depreendido de Bombassaro (1993).

Diante disso, instauram-se duas interpretações para o verbo saber. Uma ligada à crença, na qual o saber implica em crer, isto é, saber significa tomar por 
verdadeiro; e aqui se assume uma interpretação que se aproxima de uma concepção dogmática, grosso modo, sabe-se sobre aquilo que se acredita.

A outra interpretação está ligada a ideia de poder, ou seja, dizer que se sabe é o mesmo que dizer que se pode, ou ainda que se é capaz. Sob essa interpretação, vincula-se o saber ao mundo prático, assim "pois o saber revela-se em instância que vincula o homem ao mundo" (BOMBASSARO, 1993, p. 21).

Essa compreensão sobre o saber parece ser a mais significativa de ser assumida para qualquer prática pedagógica e em particular, para práticas pautadas na Investigação Matemática. Para efetivá-la, o professor deve ser capaz de realizar algumas ações. Contudo, a primeira posição relacionada ao saber, na qual o saber implica em crer, com a devida vigilância crítica, não deve ser descartada, porque há que se ter uma crença naquilo que pode ocorrer com a Investigação Matemática.

No que tange aos sentidos e significados atribuídos ao verbo conhecer, é necessário, junto a ele, um substantivo, o que não ocorre com o verbo saber. "Nisto reside uma diferença básica entre saber e conhecer, pois se conhece algo ou alguém, mas sabe-se algo acerca de algo ou alguém" (BOMBASSARO, 1993, p. 22).

Nesse sentido, conhecer também pressupõe diferenças na forma como se conhece, uma vez que conhecer algo ou alguém é diferente de conhecer algo acerca de algo ou alguém. Assim, em uma analogia com a composição entre elementos, podemos depreender que quando se conhece algo acerca de algo ou de alguém, o conhecer assume conotação de saber. Por exemplo, conhecer a Investigação Matemática não é o mesmo que conhecer as competências que se fazem necessárias ao professor para empreendê-la.

Frente à explicitação de aspectos concernentes aos termos, podemos retomar a interrogação que visamos responder: que saberes e conhecimentos são imprescindíveis ao professor ao estar-com a Investigação Matemática no ensino da matemática? 
Uma vez que o trabalho docente, como qualquer prática pedagógica, envolve ao menos duas dimensões: a do conhecimento de; e a do saber acerca de, defendemos que elas devem estar presentes e, minimamente, esclarecidas para o êxito do trabalho docente na perspectiva da Investigação Matemática. Para, além disso, devemos explicitá-las, mesmo que minimamente.

De imediato, quando se pretende trabalhar com a Investigação Matemática, parece emergir imprescindivelmente a necessidade de saber investigar. Entretanto, saber não significa conhecer e, embora sejam conceitos distintos, estão condicionados entre si. Saber trabalhar com a Investigação Matemática requer algumas habilidades no sentido de saber fazer e ser capaz de. Conhecer o trabalho com a Investigação Matemática requer conhecê-lo em sua dimensão teórica que remete ao saber investigar, num círculo não vicioso que modifica o saber e o conhecer, conforme ilustramos na figura abaixo.

Figura 1 - relação entre 'saber' e 'conhecer' no trabalho com a Investigação Matemática

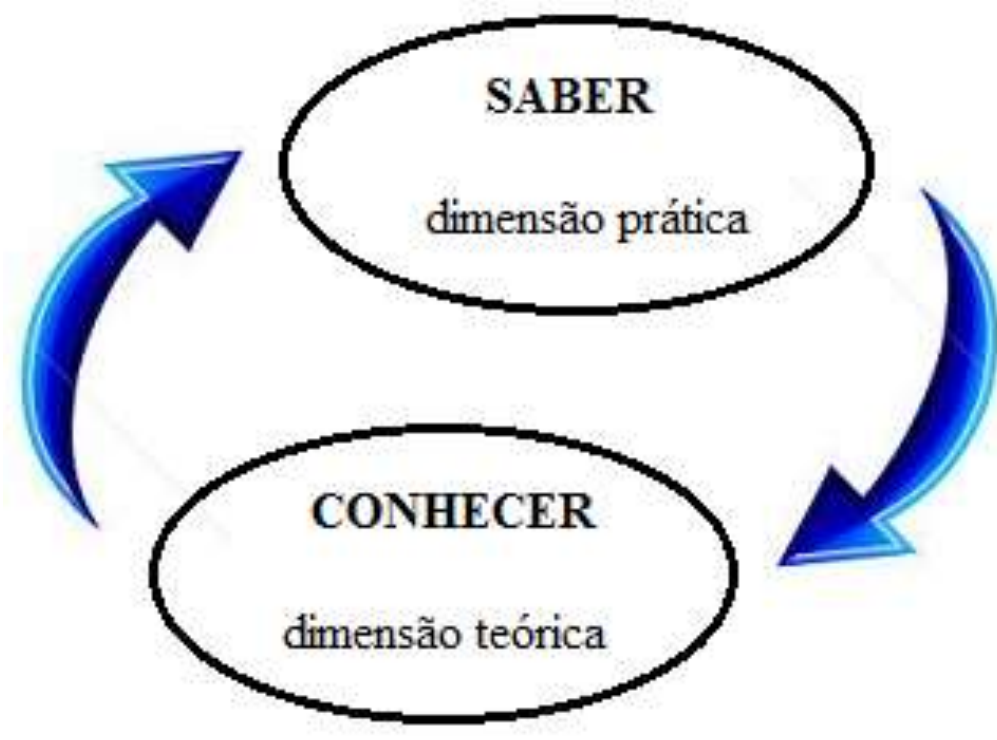

Fonte: os autores

Dessa forma, podemos pensar transitivamente, no sentido de que a aquisição dos saberes referentes à prática com a Investigação Matemática proporciona o saber investigar que por sua vez solicita e enseja conhecer (de modo próximo) como se realiza o trabalho pautado nessa tendência, incidindo na reestruturação da prática pedagógica. 
Explicitando de outra forma, conhecer o trabalho com Investigação Matemática se articula à necessidade de saber trabalhar com ela, que por sua vez implica em possuir habilidades para o trabalho investigativo e oportuniza novos conhecimentos. Contudo, a relação não é apenas lógica e nem intelectiva (teórica e cognitiva), mas experiencial. $O$ saber tem relação com a prática, com a experiência, com a vivência subjetiva.

Por outro lado, numa acepção cientificista do conhecer, o trabalho com essa tendência pode ficar restrito à dimensão intelectual de observação e mesmo livresca. Saber trabalhar com, significa, por vezes, não saber enunciar ou produzir um conhecimento explícito, mas ser capaz de. Dessa forma, saber investigar e conhecer o trabalho com Investigação Matemática são dois objetos distintos, porém não disjuntos.

Em nossa acepção teríamos assim um binômio: saber investigar e conhecer a Investigação Matemática, isto é, saber trabalhar e conhecer o trabalho com a Investigação Matemática. Enquanto 0 primeiro refere-se predominantemente à dimensão prática, o segundo refere-se à dimensão intelectual ou cognitiva.

Saber trabalhar com a Investigação Matemática não implica em conhecer o trabalho pautado nesta tendência, tendo em vista que o sujeito pode saber investigar, mas não conhecê-la do ponto de vista epistemológico. Sobre isso, Bombassaro (1993) explicita que "'conhecer X", implica "poder predicar A, B ou C de X", mas saber que "X é A, B ou C" não implica conhecer X" (BOMBASSARO, 1993, p. 22). O saber passa a ter o significado de um saber prático e indireto.

De um lado, saber trabalhar com a Investigação Matemática é possível num contexto em que exista a prevalência do paradigma investigativo (SKOVSMOSE, 2000) e práticas de Investigação Matemática recorrentes no âmbito das práticas pedagógicas. De outro, pode haver pesquisadores em Educação Matemática e professores de matemática que não sabem trabalhar com a Investigação Matemática em sala de aula, no entanto, conhecem a teoria concernente a essa tendência (intelectualmente). 
Contrapositivamente, conhecer não significa saber trabalhar com, significa tão somente poder indicar características, particularidades e peculiaridades. Isso se afina com o que indica Bombassaro (1993) quando afirma que "conhecer X", implica "poder predicar A, B ou C de X", conforme já mencionado. Essas considerações nos conduzem a argumentar de maneira mais explícita, possibilidades do que se pode entender por conhecer o trabalho com a Investigação Matemática e saber investigar matematicamente.

Entendemos que conhecer o trabalho com a Investigação Matemática diz respeito ao conhecimento dos seus pressupostos teóricos, das suas fases de execução, das suas características essenciais, bem como das competências necessárias para empreendê-lo.

Com relação ao saber investigar matematicamente, entendemos que este se dá num plano horizontal e significa descobrir relações entre objetos matemáticos conhecidos ou não, estudá-los e retirar informações que podem ou não possibilitar a solução do problema de investigação posto.

Daí deriva a implicação acima, pois saber descobrir relações, retirar informações e inferir conjecturas não são suficientes para conhecer o trabalho com a Investigação Matemática, tendo em vista que para este último são necessários, além dos citados anteriormente, saberes que extrapolam o âmbito matemático, como por exemplo, os de cunho pedagógico.

Portanto, saber investigar constitui apenas uma das etapas do trabalho de Investigação Matemática, sendo necessária, mas não suficiente. Conhecer como se realiza o trabalho de Investigação Matemática, implica em poder falar das habilidades necessárias a esse trabalho. Porém, a implicação inversa não é verdadeira.

Assim, ao interrogarmos, que saberes são imprescindíveis ao professor ao estar-com a Investigação Matemática no ensino da matemática, assumindo a segunda interpretação dada por Ryle citado por Bombassaro (1993) ao saber, estamos interrogando: que poderes são imprescindíveis ao professor na realização do trabalho com a Investigação Matemática para o ensino da 
matemática? O que o professor precisa ser capaz de para a realização do trabalho com a Investigação Matemática para o ensino da matemática?

E, ao perguntarmos que conhecimentos são imprescindíveis ao professor ao estar-com a Investigação Matemática no ensino da matemática, estamos lançando olhar sobre: o que é necessário o professor conhecer do trabalho de Investigação Matemática no ensino da matemática para a sua realização.

A ramificação da questão inicial se deu tendo em vista que, de acordo com as reflexões cunhadas sobre Bombassaro (1993), conhecer o trabalho com a Investigação Matemática, epistemologicamente, é diferente de saber acerca desse trabalho. Sendo assim, nos debruçamos sobre ela de forma a lançar olhares distintos na medida em que a colocamos em reflexão, ora enfatizando o saber, ora o conhecer.

\section{Considerações acerca dos conhecimentos}

Nesta seção lançamos o olhar específico sobre a interrogação: o que é necessário o professor conhecer para a realização do trabalho com a Investigação Matemática no ensino da matemática?

Embora seja possível usar o verbo conhecer de forma indireta, assumimos a concepção de conhecer no sentido de se referir a uma experiência direta, isto é, que conhecemos aquilo que tivemos contato, que manipulamos e que de certa maneira estamos familiarizados.

No tocante à realização do trabalho com a Investigação Matemática é imediatamente necessário que, dentre outros elementos, o professor conheça matemática. Isso nos remete ao pensamento de que o professor saiba matemática no sentido mais genuíno da expressão, tendo em vista que conhecer implica em saber, logo se conheço matemática é por que tenho saberes sobre conceitos de matemática. Retomando o que explicita Bombassaro (1993), "conhecer X", implica "poder predicar A, B ou C de X". 
Assim como é importante conhecer matemática é preciso que o professor conheça a Investigação Matemática e os aspectos que a compõem como, por exemplo, conhecer a prática de elaborar ou selecionar as tarefas, a postura a ser assumida em sala de aula, o ambiente a ser construído, entre outros. Dito de outro modo, não pode saber apenas da sua existência por intermédio de literaturas ou informações. Conhecer a Investigação Matemática significa estabelecer uma relação de proximidade. Significa investigar matematicamente.

Num primeiro momento essa afirmação pode parecer meramente pragmática, contudo ela apenas se propõe a defender que o conhecimento, como conceito que define a relação entre um sujeito e um objeto, precisa ser contemplado. Também, essa afirmação já extrapola a esfera do mero conhecer. Desse ponto de vista, nota-se que esse ato de conhecer não é puro, mas se vincula ao saber. E sob essa perspectiva, somos arremessados à esfera dos saberes.

\section{Considerações acerca dos saberes}

Partindo do pressuposto que o professor de matemática possua, pelo menos, alguns dos conhecimentos supracitados, já que, segundo Bombassaro (1993), conhecer implica em saber algo sobre, trazemos os argumentos dessa seção à luz da interrogação: que saberes são imprescindíveis ao professor na realização do trabalho com a Investigação Matemática para o ensino da matemática? Esta pode ser reescrita como: do que o professor precisa ser capaz de para a realização do trabalho com a Investigação Matemática para o ensino da matemática?

Admitindo que o professor também protagoniza o processo educativo, defendemos que a sua presença e mediação durante todo o processo do trabalho com a Investigação Matemática, tornam-se indispensáveis para o bom andamento da prática. Além disso, ele exerce um papel fundamental na inserção dessa 
tendência no currículo escolar, pois a ele cabe selecionar as atividades e conduzilas de acordo com as demandas de sua classe (CUNHA, 2009, p. 11).

Todavia, dentre as necessidades que se apresentam para realizar um trabalho de Investigação Matemática, a mais imprescindível é a de que o professor precisa saber investigar. Embora essa afirmação pareça óbvia, podemos assegurar que a obviedade contida na afirmação não se expressa na vivência que é um emaranhado de complexidade. Isso porque saber investigar requer algumas competências que não podem ser adquiridas diante da imediaticidade do sistema de ensino.

Frente a isso, aventamos, dentre outros aspectos, que saber investigar requer do professor perspectivar o ensino de matemática na forma mais genuína possível, vinculado ao ato de questionar, pensar, confrontar, errar, (re)construir e confirmar. Em outras palavras, (re)construir a matemática, uma vez que a Investigação Matemática, como ação que averigua conceitos e objetos matemáticos, está no cerne da produção do conhecimento matemático.

Impõe-se, então, a necessidade de se desfazer dos prejulgamentos e abrirse a confrontos com situações complexas e imprevisíveis. Não apenas conhecer, mas saber, ser capaz de elaborar ou adaptar tarefas, bem como assumir a postura investigativa.

Esses aspectos nos remetem a pensar que, em síntese, o que deve ocorrer é um desprendimento de certezas postas pelo modelo de ensino vigente, em particular do ensino de matemática. É preciso desprender-se da concepção de ensinar matemática centrada no uso de métodos exclusivamente analíticos, na execução de procedimentos, na aplicação de roteiros sequencialmente organizados e possuir flexibilidade de raciocínio, visto que este é um fator relevante para este tipo de trabalho.

A afirmação de que os professores precisam "perspectivar a Matemática não como uma actividade em que se memorizam definições e obtêm as respostas correctas, mas em que as acções de questionar, pensar, corrigir, confirmar são 
características essenciais" (PONTE et al., 2000, p. 17), sugere a necessidade de uma mudança epistêmica acerca daquilo que se entende por ensinar matemática.

O ensino não pode ser empreendido na concepção de um ato puramente expositivo e nem somente voltado ao conceito puramente matemático, mas também com referências no investimento das práticas pedagógicas, da relação professor-aluno e, além disso, em concepções que se opõe ao tecnicismo.

Conforme depreendemos de Ponte et al. (2003), confiança e conhecimento profissional também constituem a gama de competências referentes ao professor na realização do trabalho com a Investigação Matemática. Confiança para conduzir a aula sem receio de possíveis surgimentos de situações inesperadas e conhecimento profissional para se autoavaliar e decidir se é capaz de criar tarefas ou somente e não menos importante, adaptar e aplicar tarefas elaboradas por terceiros.

Frente a isso, um dos saberes que compete ao professor na realização do trabalho com a Investigação Matemática é a postura crítica e reflexiva no que tange aos aspectos da sua prática. Para sustentar nosso argumento, apoiamonos em Freire (2006) que afirma que ensinar exige reflexão crítica sobre a prática e "A prática docente crítica implicante do pensar certo, envolve o movimento dinâmico, dialético, entre o fazer e o pensar sobre o fazer" (FREIRE, 2006, p. 22).

Este exercício de dirigir o olhar para a própria prática possibilita mudanças significativas na postura profissional do professor, podendo mudar qualitativamente e constantemente a sua prática em sala, uma vez que, parafraseando Freire (2006), é pensando criticamente na prática de hoje ou de ontem que se pode melhorar a próxima prática.

Ainda é necessário ao professor saber trabalhar com a Investigação Matemática, que difere de conhecer o trabalho com ela, dado que saber investigar não é suficiente para o professor realizar um trabalho pautado nesta tendência.

De todas as reflexões e argumentos explicitados acima, chegamos ao desfecho desse ensaio e o explicitamos na próxima seção. 


\section{Um desfecho como abertura}

Diante do interrogado, conhecer significa conhecer do ponto de vista do objeto e saber está relacionado com o fazer. O trabalho do professor de matemática sob a perspectiva da Investigação Matemática requer a composição de diferentes aspectos, decorrentes das esferas daquilo que estamos entendendo por saber e por conhecer. Destacamos que, embora sejam conceitos distintos, não há uma dicotomia entre eles quando são assumidos como aspectos que constituem o papel do professor para o trabalho com a Investigação Matemática.

Como já afirmamos conhecer matemática não é condição suficiente para que o professor empreenda o trabalho com a Investigação Matemática, tampouco é possível empreendê-lo sem conhecer matemática, somente sabendo investigar.

O exemplo acima se sustenta na afirmação de que o trabalho amparado nessa tendência exige, além de saber investigar, que está vinculado aos aspectos de cunho pedagógico, conhecer matemática, que está vinculado aos aspectos da matemática pura. Ainda, o conhecer matemática exigido é diferente daquele que habitualmente é conhecido pelos futuros professores. É um conhecer do ponto de vista da sua construção e não da sua mera aplicação e replicação.

Segundo Ball apud Cunha (2009), os futuros professores conhecem a matemática de fornecer respostas corretas e desenvolver métodos de resolução com agilidade, entretanto não são capazes de validar e/ou explicar conceitualmente as respostas encontradas. Pensamos que esse entendimento pode ser estendido, sem generalizações ingênuas, aos professores em exercício da profissão.

Contudo, possuir a capacidade de validar e/ou explicar conceitualmente as respostas encontradas é um dos saberes intrínseco ao saber investigar que o professor deve possuir na realização do trabalho com a Investigação Matemática. Conhecer matemática do ponto de vista puro não é condição suficiente para a realização do trabalho com esta tendência, tendo em vista que ela concebe o ensino de matemática de maneira investigativa, o qual exige conhecimentos 
acerca de ensino, aprendizagem e comunicação, bem como exige saber investigar.

As reflexões efetuadas no ensaio apontam para o movimento dialético que há entre os saberes e os conhecimentos necessários para o trabalho do professor com a Investigação Matemática. Nem o saber, nem o conhecer por si só, asseguram a qualidade do trabalho na sua totalidade. É necessário que o professor saiba e conheça aspectos relacionados à Investigação Matemática para que venha a desempenhar um papel adequado (na e para a) realização do trabalho sob essa perspectiva. Do contrário, ao admitir apenas uma esfera, intelectual ou prática, há o risco de limitá-lo e até mesmo deformá-lo.

Sem dúvida apontamos, ao longo deste texto, para uma complexa relação entre saber e conhecer, o que, de imediato, pode parecer um desestímulo à adoção desta tendência. Porém, essa é uma condição a ser superada e, portanto, ainda que seja desconfortável, deve ser enfrentada, contribuindo para a superação dos atuais entraves. Sabemos que usamos o termo "deve" muitas vezes ao longo do texto. Longe de ser uma prescrição é um olhar filosófico sobre o indispensável a todos nós professores de matemática. Assim, esse termo é um norte e não todo o caminho.

\section{Referências}

ABREU, Maria das Graças dos Santos. Uma Investigação sobre a prática pedagógica: refletindo sobre a investigação nas aulas de matemática. $193 \mathrm{f}$. Dissertação de Mestrado em Educação - Universidade Federal de São Carlos, São Carlos, 2008.

BOMBASSARO, Luiz Carlos. As fronteiras da epistemologia: uma introdução ao problema da racionalidade e da historicidade do conhecimento. 2. ed. Petrópolis: Vozes, 1993.

CARNEIRO, Vera Clotilde Garcia. Formação de professores que ensinam Matemática e investigação na sala de aula: caminhos para a renovação das Licenciaturas. Boletim GEPEM, Rio de Janeiro, n. 38, 2001, p. 35-46.

CUNHA, Daniela Santa Inês. Investigações Geométricas: desde a formação do professor até a sala de aula de Matemática. 122 f. Dissertação de Mestrado em Ensino de Matemática - Universidade Federal do Rio de Janeiro, Rio de janeiro, 2009. 
FERREIRA, Miliam Juliana Alves; PAULO, Rosa Monteiro. A expressão no ciberespaço: um voltar-se fenomenologicamente para o diálogo acerca de conteúdos matemáticos. 202 f. Dissertação (Mestrado) - Programa de Pós-graduação em Educação Matemática, Universidade Estadual Paulista, Instituto de Geociências e Ciências Exatas, Rio Claro, 2014.

FREIRE, Paulo. Pedagogia da autonomia: Saberes Necessários á prática Educativa. 33. ed. São Paulo: Paz e Terra, 2006.

HESSEN, Johannes. Teoria do conhecimento. 7. ed. Coimbra: Coimbra, 1980. Tradução de: António Correia.

PONTE, João Pedro. Investigação sobre Investigação Matemática em Portugal. p. 175, 2003. Disponível em: <http://www.educ.fc.ul.pt/docentes/jponte/docs-pt/03-Ponte(RevSPCE).pdf>. Acesso em: 10 de set. de 2017.

ROCHA, Alexandra. Aprender matemática investigando. Zetetiké, v. 14, n. 26, p. 29-54, jul./dez. 2006.

BROCARDO, Joana; OLIVEIRA, Hélia. Investigações Matemáticas na sala de Aula. 3. ed. Belo Horizonte: Autêntica, 2013.

FERREIRA, Catarina; BRUNHEIRA, Lina; OLIVEIRA, Hélia; VARANDAS, José. Investigando as Aulas de Investigações Matemáticas. p.1-19, 2000. Disponível em: <http://www.prof2000.pt/users/j.pinto/textos/texto12.PDF>. Último acesso em: 01 mai. 2017.

SKOVSMOSE, Ole. Cenários para investigação. Bolema. Ano 13, n. 14, p. 66-91, 2000. 